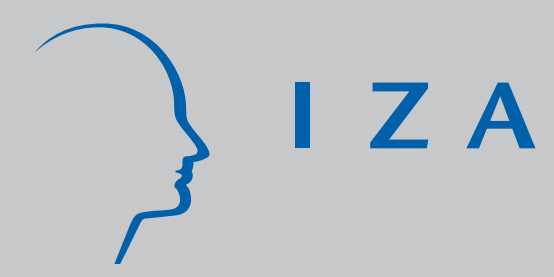

IZA DP No. 1425

Gender Differences Across the Earnings

Distribution: Evidence from NLS:86 \& HSB:92

Spyros Konstantopoulos

Amelie Constant

December 2004 


\title{
Gender Differences Across the Earnings Distribution: Evidence from NLS:86 \& HSB:92
}

\author{
Spyros Konstantopoulos \\ Northwestern University \\ and IZA Bonn \\ Amelie Constant \\ IZA Bonn
}

Discussion Paper No. 1425

December 2004

\author{
IZA \\ P.O. Box 7240 \\ 53072 Bonn \\ Germany \\ Phone: +49-228-3894-0 \\ Fax: +49-228-3894-180 \\ Email: iza@iza.org
}

\begin{abstract}
Any opinions expressed here are those of the author(s) and not those of the institute. Research disseminated by IZA may include views on policy, but the institute itself takes no institutional policy positions.

The Institute for the Study of Labor (IZA) in Bonn is a local and virtual international research center and a place of communication between science, politics and business. IZA is an independent nonprofit company supported by Deutsche Post World Net. The center is associated with the University of Bonn and offers a stimulating research environment through its research networks, research support, and visitors and doctoral programs. IZA engages in (i) original and internationally competitive research in all fields of labor economics, (ii) development of policy concepts, and (iii) dissemination of research results and concepts to the interested public.
\end{abstract}

IZA Discussion Papers often represent preliminary work and are circulated to encourage discussion. Citation of such a paper should account for its provisional character. A revised version may be available directly from the author. 
IZA Discussion Paper No. 1425

December 2004

\section{ABSTRACT}

\section{Gender Differences Across the Earnings Distribution: Evidence from NLS:86 \& HSB:92}

This study examines gender differences in the earnings of young adults in the 1980s and 1990s. We determine changes in the gender gap over time in the middle, the tails, and the variability of the earnings distribution. We employ data from two longitudinal, nationally probability samples of high school seniors: the National Longitudinal Study of high school seniors in 1972, and the High School and Beyond Study in 1980 (and the 5th and 4th followup studies respectively). We compute the average differences using effect size estimates expressed in standard deviation units. Differences in the tails and the variability are computed using number and variance ratios respectively. Adjusting for employment selection our findings reveal that once education, occupation, and marital status are taken into account gender differences in earnings (in the middle, the tails, and the variance of the earnings distribution) are eliminated. We observe similar results in gender differences for Whites, Blacks, and Hispanics.

JEL Classification: J16, J31, C10

Keywords: gender differences in earnings, general statistical methods

Corresponding author:

Amelie Constant

IZA Bonn

P.O. Box 7240

53072 Bonn

Germany

Email: constant@iza.org 


\section{Introduction}

The study of gender differences in labor market outcomes, such as earnings, has gained ample attention in economics and the social sciences. Gender differences in earnings, favoring males on average, have been researched and documented, and frequently debated in the literature. Nonetheless, there is evidence that the gender gap is decreasing over time.

The quality of the empirical evidence has not always been very strong for two main reasons. First, typically, the samples of numerous studies on gender differences in earnings are not representative of any well-defined population. Many studies use localized/convenience samples that are often times difficult to generalize to the nation as a whole. In addition, it is plausible that much of the previous research suffers from selection bias, which constitutes an important threat of external as well as internal validity (Cook \& Campbell, 1979). The main argument against selection bias is that a sample of specific individuals might not be representative of the population of individuals with the same characteristics. It is impossible to know the extent of bias in these samples; however, it is conceivable that because of selection bias the estimates reported in most of the previous studies might be very different from their "true" population parameters. In other words, it is likely that some of the results reported are positively or negatively biased.

Second, the overwhelming majority of previous studies on gender differences in earnings has exclusively examined and reported group differences in means (central tendency of the distribution of earnings). Differences in the 
variability of the earnings distribution for females and males are often times overlooked. Nonetheless, it is conceivable that the variance of the earnings distribution for females may be different that the variance of the earnings distribution for males. Notice that differences in the variance of the earnings distribution are important, since they may explain differences in the tails of the earnings distribution. For example, if males and females have comparable average earnings, but the distribution of earnings for males has a larger variance, then one would expect to find higher proportions of males in the lower and the upper tails of the earnings distribution. In addition, gender differences in the extremes (upper and lower tails) of the earnings distribution are seldom documented in the literature. It is, however, quite plausible that gender differences in the tails of the earnings distribution may be quite different qualitatively than differences in the middle of the distribution. For example, males may be overrepresented in the top $10 \%$ of the earnings distribution compared to females, a byproduct of over-concentration of men in highly paid jobs. Similarly, females may be over-represented in the lower tail of the earnings distribution. These differences may not necessarily be in congruence with gender differences on average.

This study employs base year and follow-up samples of national probability samples of high school sophomores and seniors, and examines gender differences in earnings across the whole distribution of earnings for young adults. Specifically, we use information from the fifth follow-up of the National Longitudinal Study (NLS:86) of the High School Class of 1972 and the 
base year and fourth follow-up of the High School and Beyond (HSB:92) survey of 1980 . These rich data sets allow us to examine the labor market performance of individuals some 14 and 10 years after high school graduation respectively.

Because of the use of national probability samples our results are more likely to have higher external validity (generalizability) and be more resilient to threats of selection bias. We examine gender differences in earnings for young adults in the 1980s and 1990s across the whole distribution of earnings. Specifically, we determine the gender gap in earnings on average (central tendency), in variability (variance), and extreme values of income (either very high, top $5,10 \%$, or very low income, bottom $5,10 \%$ ). We also examine gender differences in earnings adjusting for social class (education and occupation) and marital status, since such covariates can play a very important role in the gender gap. For example, controlling for education and occupation should in principle equate individuals for skills, knowledge, and productivity, preferences in the labor market (Mutari \& Figart, 2003). Similarly, controlling for marital status should adjust for differences due to household responsibilities. In addition, we examine gender differences in earnings across the entire distribution of earnings within three major race/ethnic groups: Blacks, Hispanics, and Whites. This allows us to determine whether the gender gap differs across the three main race/ethnic groups.

The remainder of this study is structured as follows. First, findings of previous research on gender differences in earnings are summarized. Second, 
we outline our data and the methods we used to analyze them. Third, the results of the analysis are presented, and fourth, concluding remarks are drawn.

\section{Related Literature}

Research on the gender earnings gap has documented that, on average, the earnings of white males are considerable higher than those of females. In fact, the finding that on average white males earnings are considerably higher than those of white females and other race/ethnic groups is well established in the labor economics literature (Carnoy, 1996; Durden \& Gaynor, 1998). In addition, these gender and race/ethnicity earnings differentials persist even after adjusting for human capital and labor market characteristics. In fact, there is some evidence that gender effects are substantially larger than race/ethnicity effects (Durden \& Gaynor, 1998; Corcoran \& Duncan, 1979). A very recent study provided further support to this notion by reporting that schooling is important in explaining race but not gender earnings differentials (England et al., 1999).

Nonetheless, the hourly wage difference between men and women has narrowed between the mid 1970s and the late 1980s (O'Neill \& Polachek, 1993). This earnings convergence is oftentimes partly attributed to increases in women's work experience, years of schooling, and other skill acquisition. For instance, Blau and Kahn (1997) postulate that the closure of the gender gap in wages is not only attributed to improvements in women's occupational status and experience, but also to enhancements in women's unmeasured labor skills and/or a decrease in discriminating against them. Moreover, the black-white as 
well as the Latino-white wage differential has decreased between 1940 and 1980 (Smith \& Welch, 1986, 1989). Indeed, blacks and Latinos made large gains in education and earnings during the last 50 years. To conclude, even though gains in schooling contributed in reducing the minority-white earnings gap, this contribution is rather small, especially for blacks.

Earnings are a function of health, education, training, and experience in the labor market. According to human capital theory, education enhances labor market productivity and, therefore, earnings (Becker, 1964). In fact, education is pivotal to human capital formation, and investments in human capital have been hypothesized to yield sizable economic and social rates of return. The main hypothesis is that higher levels of education correspond to higher levels human capital, which in turn results in higher labor market performance and higher paying jobs. To that end, we also explore gender differences in earnings controlling for educational attainment. ${ }^{1}$

We also examine gender differences in earnings controlling for occupational status. ${ }^{2}$ Occupational status is a proxy for choices and preferences in the labor market (Mutari \& Figart, 2003). It is also a proxy of the market's evaluation of an individual's skills and potential. We are interested in determining gender differences in earnings net of the effects of occupational status, or examine the gender gap for persons with the same occupational status.

\footnotetext{
${ }^{1}$ We control for educational attainment using a dummy that takes the value of one if the individual has a college degree or more and zero otherwise.

${ }^{2}$ We control for occupational status using two dummies: one for professional and one for white-collar workers. The blue-collar workers category serves as the comparison group.
} 
Finally, previous findings have reported that marital status is an important correlate of earnings. Specifically, marital status signals productivity to the labor market and affects potential tenure on the job, hence positively affecting earnings. It has been repeatedly found that in the U.S. married men earn substantially more than unmarried men even after controlling for human capital and race (Bartlett \& Callahan, 1984; Korenman \& Neumark, 1991). More recent studies have replicated these findings in other developed countries suggesting that the married-unmarried men gap in average earnings might be ubiquitous (Schoeni, 1994). In fact, Schoeni reported that wage differences are evident even among those men who are currently not married. For example, separated or widowed men earn significantly more than men who are never married. For that reason, we also examined gender differences in earnings net of the effects of marital status. ${ }^{3}$

\section{Method}

\section{Data Sets}

We employ two rich, longitudinal, and representative samples of individuals who were high school students in 1972 and in 1980 and wage earners in 1986 and 1992 respectively. Specifically, we draw upon the National Longitudinal Study (NLS) of the High School Class of 1972 and the fifth follow-up in 1986, as well as on the High School and Beyond (HSB) surveys of 1980, 1982, and the fourth follow-up in 1992 . NLS-72 is a national probability sample of high

\footnotetext{
${ }^{3}$ We control for marital status using a dummy that takes the value of one if the individual is married or living under common law and zero otherwise.
} 
school seniors designed to represent all twelfth graders enrolled in public or private American high schools in the spring of 1972 (Riccobono et al., 1981). These students were followed for 14 years after high school, and, thus, they were resurveyed in $1974,1975,1977,1980$, and 1986 . We employ data collected during the base-year survey in 1972 and the fifth follow-up in 1986 . Our final sample includes all individuals who were present in 1972 and in 1986 and were not in the military.

In the spring of 1980, two cohorts of tenth and twelfth grade students enrolled in public and private schools in the US were surveyed for the HS\&B-80. This study targeted students who were high school sophomores and seniors in 1980 enrolled in public or private American schools. Both cohorts (the sophomore and senior class of 1980) were followed for six years and, thus, were resurveyed every two years through 1986. Only the sophomore class was surveyed again for the fourth time in 1992. Our final sample for the HS\&B-80 includes individuals who were present in the base year, the first, and the fourth follow-up samples, and were not in the military in 1992. Hence, our sample consists of individuals who were high school sophomores in 1980.

Both datasets are unique in providing valuable information on the educational attainment, occupational status, and employment outcomes of young adults in 1986 and 1992. Both NLS and HSB are longitudinal studies, which are part of the program of the National Center for Education Statistics (NCES) established to study the educational, vocational, and personal development of young people. Their longitudinal feature allows us to follow these students 10 to 
14 years after their high school graduation and examine their labor market performance during their prime time in the labor market. In addition, because we are also looking at students who have been in the labor market for a decade or more we avoid any biases from school to work transitions. Typically, individuals tend to be more settled and change jobs less often after the first decade of employment.

Using the NLS fifth follow-up and the HSB fourth follow-up made it possible to examine gender differences in employment outcomes for young adults at the age of 30 at their peak of labor force participation and remuneration. Our sample incorporated individuals with various levels of education to ensure the inclusion of all persons who reported positive earnings in 1986 and 1992.

\section{$\underline{\text { Analysis }}$}

Since workers may differ from non-workers in unobservable ways we adjust our models for possible selection bias. Specifically, following Heckman (1979) we use a probit model that estimates possible selection in the labor force for the entire sample. Our predictors include educational attainment, marital status, and nonlabor income (income from interest, social security and veteran benefits, welfare, unemployment compensation, gifts, scholarships, etc). We hypothesize that a college degree will increase the probability to work, while high nonlabor income will decrease the probability to work by increasing the reservation wage. In addition, we expect married individuals to have a higher probability to work since marital status has been shown to signal labor force 
attachment and higher productivity in the labor market affecting potential tenure on the job (e.g., Korenman \& Neumark, 1991). From the probit model we calculate the so-called inverse Mill's ratio or $\lambda$, which we take into account when computing gender differences in earnings to adjust for possible non-random selection of workers. Note that all analyses are corrected for selection in the labor force, and therefore all results presented in this study in the following section are adjusted for potential selection bias.

A standard method to assess group differences in means is to compute effect sizes. An effect size is simply a standardized mean difference between two groups. To examine average gender differences in earnings we calculate effect sizes by subtracting the estimated national mean of earnings for males from that for females and dividing by the estimated national standard deviation (SD) of earnings for the entire distribution with both gender groups included. We used sampling weights to construct estimates for the national means and the national standard deviations for both groups. Because of the standardization the effect sizes are expressed in standard deviation units, which makes them easier to interpret. For example, an effect size of one would indicate that the average difference in earnings between females and males is one standard deviation. Negative values indicate that the difference favors males, while positive values indicate that the difference favors females.

Differences in the variability of the distribution of earnings among groups were gauged using the variance ratio (Hedges \& Nowell, 1999). This ratio is simply the square of the ratio of the standard deviation of the earnings 
distribution for females to that of the earnings distribution for males. A ratio greater than one indicates that the variance of the female distribution of earnings is larger than that of male, while a ratio smaller than one indicates that the variance of the male distribution of earnings is larger.

Group differences in the upper and the lower tails of the earnings distribution were estimated by the ratio of the proportion of individuals who are females, to that of males in a specific location of the distribution (Hedges \& Nowell, 1999). To accomplish that, we first constructed national percentiles for the entire distribution of earnings with all groups included using weights. Then, we estimated the proportion for individuals for each group who fell in the predefined national percentiles. For example, we estimated the proportion of females who were in the upper $5,10 \%$ of the total distribution of earnings. In other words, we assessed the proportions for each group (females and males) that had extreme values of earnings (either too high or too low). We estimated these proportions for the bottom and the top 25,10 , and $5 \%$ of the entire distribution of earnings. Once the proportions for each group were estimated, we constructed a ratio of the estimated proportion for females to the estimated proportion for males. If the representation of the two groups were the same in the specific percentiles of the distribution, one would expect to obtain ratios of one. Ratios greater than one indicate over-representation of females over males for a specific percentile, and similarly, ratios smaller than 1one indicate underrepresentation of females over males. 
Gender differences in earnings were also examined adjusting for social class (occupational status and educational attainment) and marital status in 1986 and 1992. We hypothesize that such variables can play an important role in gender differences in earnings. In particular, we expect that the gender gap in earnings will be smaller after having taken into account these covariates. To carry out these analyses, we regressed the earnings for both groups on their education, occupation, and marital status. The residuals of this linear regression served as the new/adjusted distribution of earnings net of the effects of social class and marital status. Then, the same methods discussed earlier were employed for estimating gender differences in means, variability, and the upper and lower tails. Finally, the same methods were employed to examine unadjusted and adjusted gender differences in earnings for Blacks, Hispanics, and Whites. Again, note that all analyses are also corrected for selection in the labor force.

Results and Discussion

\section{Descriptive Statistics: NLS, HSB}

Table 1 summarizes the descriptive statistics for selected variables in the base year and fifth follow-up samples of NLS for the entire sample and by gender category. Overall, our sample consists of $51 \%$ women and $49 \%$ men. Nearly $10 \%$ of our sample are Blacks, $3 \%$ are Hispanics, and $82 \%$ are Whites. On average, women in 1986 while in their early thirties earn $40 \%$ less than men 
(nearly $\$ 11,000$ less annually). When we break annual earnings ${ }^{4}$ by race, we see that minority women earn nearly as much as White women, while minority men, Blacks in particular, earn $20 \%$ less than White men, and Hispanic men nearly $10 \%$ less than White men. These statistics also show that although a smaller percentage of women than men have finished college in 1986 , still $1 / 4$ of them have acquired a college degree. The majority of both women and men in our 1986 sample are married but a higher percentage of women than men are in the divorced category. The majority of individuals in our sample are white collar workers. Women are mainly in white collar or professional jobs $(80 \%)$, while men are mainly in blue collar jobs.

\section{Insert Table 1 Here}

Table 2 illustrates the descriptive statistics for selected variables in the base year and fourth follow-up samples of HSB for the entire sample and by gender category. Overall, our sample consists of $52 \%$ women and $48 \%$ men. Eleven percent of our sample are Blacks, nearly $13 \%$ are Hispanics, and $74 \%$ are Whites. On average, women in 1992 while in their late twenties earn $1 / 4$ less than men (nearly $\$ 6,000$ less annually). The gender gap in 1992 is almost one half as large as in 1986. Again, as in NLS:86 minority women earn nearly as much as White women, while minority men, Blacks in particular, earn $20 \%$ less than White men annually. It is noteworthy that Hispanic men earn about $7 \%$ more

\footnotetext{
${ }^{4}$ We are using annual earnings because our data sets do not have information on hourly wages nor hours of work. We only have information on full- or part-time work.
} 
than White men annually. In 1992 equal proportions of men and women have acquired a college degree. The majority of both women and men in our 1992 sample are married but a higher percentage of men than women are single. As in 1986, the majority in our sample are white collar workers. As previously, women are mainly in white collar or professional jobs $(75 \%)$, while men are mainly in blue collar jobs.

Insert Table 2 Here

\section{Primary Analyses: NLS, HSB}

The average gender gap in earnings was $3 / 4$ of a standard deviation (SD) favoring males in 1986 (see Table 3). This is a rather large difference according to standard criteria for evaluating effect sizes (Cohen, 1977). However, once social class and marital status were controlled for, the average gender gap in earnings was practically zero, and the two groups reached parity. The unadjusted average gender gap in earnings was a little less than $1 / 2$ of a SD favoring males in 1992. This indicates that the gender gap decreased by approximately $1 / 3$ from 1986 to 1992 . This is a moderate difference according to standard criteria for evaluating effect sizes (Cohen, 1977). As in NLS:86, once social class and marital status were taken into account the average gender gap in earnings was practically zero, and the two groups reached parity.

Similar patterns were observed for the majority group (Whites) and the two minority groups (Black, Hispanics). The gender gap was consistently smaller in 
1992 and almost non-existent once social class and marital status were taken into account. In 1992 the unadjusted gender gap for Blacks was about 1/10 of a SD and the adjusted gap was practically zero, while in 1986 the adjusted gender gap was $1 / 10$ of a SD favoring males. It is noteworthy that the adjusted gender gap for Hispanics was positive in 1986, indicating that once social class and marital status are controlled for Hispanic women earn on average about $1 / 10$ of a SD more than Hispanic men.

Insert Table 3 Here

Table 4 presents the unadjusted gender differences in number ratios in the tails of the earnings distribution. In 1986 there were four to eight times more women than men in very low earning jobs. In contrast, there were four times as many men in very high paying jobs. In 1992 however, the gender gap was less pronounced in the tails of the earnings distribution. There were two to three times more women in low paying jobs, and two to three times more men in high paying jobs. The results for Whites and Hispanics were quite comparable. Overall, women were under-represented in the upper tail and over-represented in the lower tail. The gender gap was reduced notably in 1992 for Whites, but remained unchanged for Hispanics. The gender gap for Blacks was much smaller than that for Whites or Hispanics, especially in 1992.

Insert Table 4 Here 
The adjusted gender differences in number ratios in the tails of the earnings distribution are illustrated in Table 5. In 1986 there were equal number of women and men in very low earning jobs. Interestingly, there were 1.5 times as many women as men in very high paying jobs. In 1992, the two sexes reached parity in the tails of the earnings distribution. The results for Whites and Hispanics were comparable. Is it noteworthy that White women were 1.7 times more likely to be in a high paying job than White men in 1986. For Hispanics the female advantage was somewhat smaller in 1986. However, in 1992 Hispanic men were twice as likely to be in high paying jobs as Hispanic women. Overall, for Blacks the two sexes were almost equally represented in the tails of the earnings distribution.

Insert Table 5 Here

Gender differences in the variability of the earnings distribution are summarized in Table 6 . The unadjusted earnings distribution for females is much more spread out than that of males. In 1986, the variance of the female earnings distribution was more than two times larger than that of males, and in 1992 it was 1.7 times as large. This explains the over-representation of females in the lower tails of the distribution and partially the under-representation of females in the upper tail (since the average gap was less than $3 / 4$ of a SD in 1986 and less that $1 / 2$ of a SD in 1992). This difference in variability was evident for all race/ethnic 
groups in 1986 and 1992. The only exception in 1992 was Hispanics, where the male earnings distribution was more spread out than that of the females. Nonetheless, the variances of the adjusted for social class and marital status distributions of the two sexes are equal in 1986 and 1992. This finding holds across all race/ethnic groups; that is adjusted gender differences in variability were almost non-existent both in 1986 and 1992 for all groups.

Insert Table 6 Here

\section{Conclusion}

This study examined gender differences in annual earnings employing two rich data sets of representative samples of high school seniors. We explored the gender gap across and within racial/ethnic groups, also adjusting for social class (human capital) and marital status, as well as for selection in the labor force.

Overall, men earn on average higher income than women in the 1980 s and 1990s. Nonetheless, the gender gap is decreasing over time and it is much smaller in the 1990s. Specifically, the gender gap in earnings was $1 / 3$ smaller in 1992 than in 1986. It is noteworthy however, that once educational attainment, occupational status, and marital status are taken into account the gap disappears. This indicates that men and women with the same education, occupation, and marital status have comparable annual earnings. This result 
holds for our entire samples and for the majority, minority ethnic groups. In 1992 all adjusted gender differences in earnings are close to zero and non significant.

Typically, men are over-represented in the higher end of the earnings distribution, while women are over-represented in the lower end. The tail gap is much more pronounced in 1986 than in 1992 for all groups except Hispanics. For Hispanics the gender gap in the tails remained unchanged. However, these gender differences disappear for all groups once social class and marital status are controlled for. This indicates that the covariates influenced similarly the gender gap in the middle and the tails of the earnings distribution. In 1992 men and women with the same education, occupation, and marital status reached parity across the entire distribution of earnings.

It is interesting that the female distribution of earnings is more diverse than that of men in NLS and HSB. The variance of the female earnings distribution was twice as large as that of males in 1986. This partly explains the overrepresentation of women in the lower tails of the earnings distribution in NLS given that the average difference of the two distributions was $0.75 \mathrm{SD}$. The variance of the female earnings distribution was less than twice as large than that of males in 1992 (approximately a 15\% reduction in the variance difference). Given that the average gender gap in 1992 was a little less than 0.5 SD this difference in variability partly explains the reduced over-representation of women in the lower tails of the earnings distribution in HSB, and the slightly less underrepresentation of women in the upper tail. Gender differences in variability followed similar patterns for Whites and Hispanics, although the variance ratio 
became larger in 1992 for Hispanics, but not for Blacks. Gender differences in variability were smaller within Blacks, and in 1992 the male distribution was more spread out than that of the females. In line with patterns in the middle and the tails of the distribution the adjusted gender differences in variability were absent. The male and female distributions had similar variance once important covariates were taken into account.

In sum, our findings indicate that once educational attainment, occupational status and marital status are taken into account, on average males and females earn comparable average, low, or high income. Gender differences in variability are also eliminated. Both in 1986 and in 1992 the gender gap in earnings is practically zero when social class and marital status are controlled for, across the entire distribution of earnings. It is actually noteworthy that in NLS:86 there are one and one half as many females in the upper tail of the adjusted earnings distribution as males. In addition the variance ratios are very close to one. Our specifications indicated that that the unadjusted gender gap is fully explained and removed once social class and marital status are taken into account. 


\section{References}

Becker, G. S. (1964). Human capital: A theoretical and empirical analysis with special reference to education. New York: Columbia University Press.

Bartlett, R. L. and C. Callahan. 1984. "Wage Determination and Marital Status: Another Look." Industrial Relations 23(Winter):90-96.

Blau, F. D. and L. M. Kahn. 1997. "Swimming Upstream: Trends in the Gender Wage Differential in the 1980s." Journal of Labor Economics 15: 1-42.

Blau, F. D. and A. H. Beller. 1992. "Black-White Earnings Over the 1970s and 1980s: Gender Differences in Trends." The Review of Economics and Statistics : 276-86.

Carnoy, M. 1996. "Education and Racial Inequality: The Human Capital Explanation Revisited." Economics of Education Review 15:259-72.

Cohen, J. (1977). Statistical power analysis for the behavioral sciences. New York: Academic Press.

Cook, T. D. and D. T. Campbell. (1979). Quasi-experimentation. Boston, MA: Houghton Mifflin.

Corcoran, M. and G. J. Duncan. 1979. "Work History, Labor Force Attachment, and Earnings Differences Between the Races and Sexes." Journal of Human Resources 140:3-20.

Durden, G. C. and P. E. Gaynor. 1998. "More on the Cost of being Other Than White and Male: Measurement of Race, Ethnic, and Gender Effects on yearly Earnings." American Journal of Economics and Sociology 57(Jan.): 95-103.

England, P., K. Christopher, and L. L. Reid. 1999. "Gender, Race, Ethnicity, and Wages." In Latinas and African American Women at Work, edited by Irene Browne, pp 139-182. New York: Russell Sage.

Heckman, J. J. (1979). "Sample Selection Bias as a Specification Error." Econometrica, 47, 475-492.

Hedges, L. V., and A. Nowell. (1999). "Changes in the Black-White gap in achievement test scores." Sociology of Education, 72, 111-135.

Korenman, S. and D. Neumark. 1991. "Does Marriage Really Make Men More Productive?" Journal of Human Resources, 26(2): 282-307. 
Mutari, E., and D. B. Figart. (2003). Women and the Economy. Armonk, NY: M. E. Sharpe.

O'Neill, J. and S. Polachek. 1993. "Why the Gender Gap in Wages Narrowed in the 1980s." Journal of Labor Economics 11: 205-28.

O'Neill, J. 1990. "The Role of Human Capital in Earnings Differences Between Black and White Men." Journal of Economic Perspectives 4: 25-45.

Riccobono, J., L. B. Henderson, G. J. Burkheimer, C. Place, and J. R. Levinsohn. 1981. National Longitudinal Study. Research Triangle Institute.

Schoeni, R. F. 1995. "Marital Status and Earnings in developed Countries." Journal of Population Economics 8:351-59.

Smith, J. and F. R. Welch. 1989. "Black Economic Progress after Mydral." Journal of Economic Literature 27(June): 519-64.

Smith, J. and F. R. Welch. 1986. Closing the Gap: Forty years of Economic Progress for Blacks. Santa Monica, CA: Rand Corp. 
Gender Differences in Earnings 23

Table 1. Arithmetic Means and Proportions for Selected Variables by Gender: NLS

\begin{tabular}{lrrr}
\hline & U.S. Population & Female & Male \\
\hline Individual Characteristics & & & \\
Female & $50.9 \%$ & \multicolumn{1}{l}{} & - \\
Male & $49.1 \%$ & - & - \\
& & & \\
Black & $9.7 \%$ & $11.3 \%$ & $8.0 \%$ \\
Hispanic & $3.3 \%$ & $3.2 \%$ & $3.5 \%$ \\
White & $82.2 \%$ & $81.2 \%$ & $83.2 \%$ \\
& & & \\
Professional & $21.2 \%$ & $23.3 \%$ & $19.1 \%$ \\
White Collar & $46.7 \%$ & $58.0 \%$ & $35.7 \%$ \\
Blue Collar & $32.1 \%$ & $18.8 \%$ & $45.1 \%$ \\
& & & \\
College Degree or More & $26.0 \%$ & $24.7 \%$ & $27.4 \%$ \\
& & & \\
Single & $17.1 \%$ & $15.3 \%$ & $18.8 \%$ \\
Married & $67.7 \%$ & $67.9 \%$ & $67.6 \%$ \\
Divorced-Separated-Widowec & $10.5 \%$ & $12.3 \%$ & $8.6 \%$ \\
Living in Common Law & $3.8 \%$ & $3.8 \%$ & $3.9 \%$ \\
& & & \\
Annual Earnings & & & \\
All Groups & 21,754 & 15,859 & 26,660 \\
Blacks & 18,254 & 15,811 & 21,451 \\
Hispanics & 20,736 & 16,315 & 24,166 \\
Whites & 22,316 & 15,950 & 27,409 \\
\hline
\end{tabular}


Gender Differences in Earnings 24

Table 2. Arithmetic Means and Proportions for Selected Variables by Gender: HSB

\begin{tabular}{lrrr}
\hline & U.S. Population & Female & Male \\
\hline Individual Characteristics & & & \\
Female & $51.6 \%$ & - & - \\
Male & $48.4 \%$ & - & - \\
& & & \\
Black & $11.3 \%$ & $12.1 \%$ & $10.5 \%$ \\
Hispanic & $12.5 \%$ & $11.4 \%$ & $13.7 \%$ \\
White & $74.0 \%$ & $74.6 \%$ & $73.4 \%$ \\
& & & \\
Professional & $14.9 \%$ & $19.3 \%$ & $10.8 \%$ \\
White Collar & $46.8 \%$ & $56.1 \%$ & $38.2 \%$ \\
Blue Collar & $36.4 \%$ & $24.2 \%$ & $47.6 \%$ \\
& & & \\
College Degree or More & $25.4 \%$ & $25.2 \%$ & $25.5 \%$ \\
& & & \\
Single & $37.1 \%$ & $30.5 \%$ & $44.1 \%$ \\
Married & $52.8 \%$ & $58.0 \%$ & $47.2 \%$ \\
Divorced-Separated-Widowec & $9.3 \%$ & $10.7 \%$ & $7.8 \%$ \\
Living in Common Law & $0.8 \%$ & $0.8 \%$ & $0.8 \%$ \\
& & & \\
Annual Earnings & & & \\
All Groups & 22,450 & 19,101 & 25,489 \\
Blacks & 19,627 & 18,339 & 20,895 \\
Hispanics & 23,071 & 17,045 & 27,629 \\
Whites & 22,706 & 19,450 & 25,734 \\
\hline
\end{tabular}


Gender Differences in Earnings 25

Table 3. Average Gender Differences in Earnings for the Entire Sample and for Different Ethnic/Race Groups

\begin{tabular}{lcccc}
\hline & \multicolumn{4}{c}{ Unadjusted } \\
\hline Survey & Entire Sample & Blacks & Hispanics & Whites \\
\hline NLS:86 & $-0.760^{*}$ & $-0.478^{*}$ & $-0.687^{*}$ & $-0.794^{*}$ \\
HSB:92 & $-0.443^{*}$ & $-0.120^{*}$ & $-0.536^{*}$ & $-0.487^{*}$ \\
& & \multicolumn{5}{c}{ Adjusted } \\
\hline Survey & Entire Sample & Blacks & Hispanics & Whites \\
\hline NLS:86 & 0.005 & -0.104 & 0.119 & 0.019 \\
HSB:92 & -0.010 & 0.001 & -0.063 & -0.010 \\
\hline
\end{tabular}

${ }^{*} p<0.05$ 
Table 4. Unadjusted Gender Differences in Number Ratios in Earnings for the Entire Sample and for Different Ethnic/Race Groups

\begin{tabular}{|c|c|c|c|c|c|c|}
\hline \multirow{3}{*}{ Survey } & \multicolumn{6}{|c|}{ Unadjusted } \\
\hline & \multicolumn{6}{|c|}{ Entire Sample } \\
\hline & Bottom 5 & Bottom 10 & Bottom 25 & Top 25 & Top 10 & Top 5 \\
\hline NLS:86 & 8.07 & 4.27 & 3.34 & 0.28 & 0.24 & 0.22 \\
\hline HSB:92 & 3.24 & 2.38 & 1.85 & 0.51 & 0.38 & 0.33 \\
\hline \multirow[t]{2}{*}{ Survey } & \multicolumn{6}{|c|}{ Blacks } \\
\hline & Bottom 5 & Bottom 10 & Bottom 25 & Top 25 & Top 10 & Top 5 \\
\hline NLS:86 & 1.89 & 1.42 & 1.74 & 0.41 & 0.46 & 0.23 \\
\hline HSB:92 & 0.84 & 0.99 & 1.34 & 0.62 & 0.38 & 0.48 \\
\hline \multirow[t]{2}{*}{ Survey } & \multicolumn{6}{|c|}{ Hispanics } \\
\hline & Bottom 5 & Bottom 10 & Bottom 25 & Top 25 & Top 10 & Top 5 \\
\hline NLS:86 & 4.07 & 3.14 & 2.73 & 0.31 & 0.36 & 0.38 \\
\hline HSB:92 & 4.58 & 3.15 & 2.01 & 0.42 & 0.32 & 0.32 \\
\hline \multirow[t]{2}{*}{ Survey } & \multicolumn{6}{|c|}{ Whites } \\
\hline & Bottom 5 & Bottom 10 & Bottom 25 & Top 25 & Top 10 & Top 5 \\
\hline NLS:86 & 9.43 & 5.12 & 3.68 & 0.28 & 0.24 & 0.21 \\
\hline HSB:92 & 3.84 & 2.81 & 1.96 & 0.49 & 0.39 & 0.31 \\
\hline
\end{tabular}


Table 5. Adjusted Gender Differences in Number Ratios in Earnings for the Entire Sample and for Different Ethnic/Race Groups

\begin{tabular}{|c|c|c|c|c|c|c|}
\hline & \multicolumn{6}{|c|}{ Adjusted } \\
\hline Survey & \multicolumn{6}{|c|}{ Entire Sample } \\
\hline & Bottom 5 & Bottom 10 & Bottom 25 & Top 25 & Top 10 & Top 5 \\
\hline NLS:86 & 1.11 & 1.03 & 1.09 & 1.07 & 1.25 & 1.53 \\
\hline HSB:92 & 1.04 & 1.04 & 1.04 & 1.02 & 0.93 & 0.99 \\
\hline Survey & \multicolumn{6}{|c|}{ Blacks } \\
\hline & Bottom 5 & Bottom 10 & Bottom 25 & Top 25 & Top 10 & Top 5 \\
\hline NLS:86 & 0.65 & 1.12 & 1.26 & 0.99 & 0.98 & 0.73 \\
\hline HSB:92 & 1.24 & 1.23 & 1.04 & 1.02 & 0.82 & 0.90 \\
\hline Survey & \multicolumn{6}{|c|}{ Hispanics } \\
\hline & Bottom 5 & Bottom 10 & Bottom 25 & Top 25 & Top 10 & Top 5 \\
\hline NLS:86 & 1.04 & 0.99 & 1.14 & 1.27 & 1.47 & 1.44 \\
\hline HSB:92 & 1.03 & 1.20 & 1.11 & 0.92 & 0.85 & 0.53 \\
\hline Survey & \multicolumn{6}{|c|}{ Whites } \\
\hline & Bottom 5 & Bottom 10 & Bottom 25 & Top 25 & Top 10 & Top 5 \\
\hline NLS:86 & 1.07 & 0.99 & 1.06 & 1.07 & 1.23 & 1.68 \\
\hline HSB:92 & 1.05 & 1.04 & 1.04 & 1.03 & 0.95 & 1.09 \\
\hline
\end{tabular}


Gender Differences in Earnings 28

Table 6. Gender Differences in Variability in Earnings for the Entire Sample and for Different Ethnic/Race Groups

\begin{tabular}{|c|c|c|c|c|}
\hline & \multicolumn{4}{|c|}{ Unadjusted } \\
\hline Survey & Entire Sample & Blacks & Hispanics & Whites \\
\hline$\overline{N L S: 86}$ & 2.31 & 1.40 & 1.61 & 2.45 \\
\hline \multirow[t]{2}{*}{ HSB:92 } & 1.65 & 0.77 & 2.06 & 1.88 \\
\hline & \multicolumn{4}{|c|}{ Adjusted } \\
\hline Survey & Entire Sample & Blacks & Hispanics & Whites \\
\hline $\begin{array}{l}\text { NLS:86 } \\
\end{array}$ & 1.07 & 1.20 & 0.80 & 1.05 \\
\hline HSB:92 & 1.14 & 0.98 & 1.05 & 1.21 \\
\hline
\end{tabular}

